\title{
INDIVIDUAL DIFFERENCES IN AGGRESSIVENESS OF FEMALE HAMSTERS: RESPONSE TO INTACT AND CASTRATED MALES AND TO FEMALES
}

\author{
BY DAVID M. MARQUES \& ELLIOT S. VALENSTEIN \\ Department of Psychology, University of Michigan, Ann Arbor, Michigan 48104
}

\begin{abstract}
The aggressive behaviour of female hamsters was studied while they were housed in large enclosures with males and in brief tests with males or females. Some females are not aggressive with any male, whereas others are very aggressive toward all males in both testing conditions. Females that are not aggressive toward intact males may be very aggressive toward castrated males or females. When the animals are housed together for long periods of time, males dominate only if they are much heavier. Male dominance takes a relatively long time to establish and often there is an equivocal period characterized by reversals of doinance. Female dominance is rapidly established. Unless the male is much heavier, the female determines the presence or absence of agonistic behaviour.
\end{abstract}

In most mammalian species the male is heavier and more aggressive than the female and is dominant over females in many situations. This difference between the sexes may be a major determinant of the social patterns that prevail, but there is little direct support for this hypothesis. A study of the social behaviour in those few mammals where the female is more aggressive and dominant may be useful in this regard. The hamster (both the Syrian golden hamster, Mesocricetus auratus, Waterhouse, and the European hamster, Cricetus cricetus) is the most notable exception to the commonly found sex difference in aggressiveness, but there exist sparse and sometimes conflicting data suggesting that the female may be more aggressive in chinchillas (Elliott 1955; Klauer 1969), some species of lemurs (Jolly 1966) and vervet monkeys according to Rowell (1971), but not according to Struhsaker (1967).

Although the data are not extensive the aggression-dominance relationship between the sexes appears to have a marked influence on the social interactions among hamsters. According to Eibl-Eibesfeldt (1953), the European hamster is a solitary creature in the wild. The female accepts the male for up to a week following mating, after which time she chases him away. In both the European and Syrian golden hamster, a male rarely attacks a female and may not even defend itself against the often severe attacks of the unreceptive female (EiblEibesfeldt 1953; Dieterlin 1959). Most investigators report that female aggression against males increases with the approach of parturition and the presence of pups (Eibl-Eibesfeldt 1953; Dieterlen 1959; Leonard 1972), although there is one short report to the contrary (Melton 1950). Dieterlen (1959) did describe two females that permitted males to approach their young and even to participate in 'active litter care', but little was made of this observation. The males in both these cases were seen to carry the pups at least once, and one was observed licking the pups and relocating the nest. It is not known if this behaviour occurs in the wild, where the male would be able to leave the nest area.

The female golden hamster has been reported to be heavier than the male (Dieterlen 1959; Lawlor 1963; Swanson 1967; Lerwill 1968), although we have found no significant sexual dimorphism in bodyweight. In the hamster, intrasexual aggression is highly correlated with bodyweight (Payne \& Swanson 1970; Drickamer, Vandenbergh \& Colby 1973; Drickamer \& Vandenbergh 1973). Both males and females generally exhibit considerable aggression when placed together in homosexual pairs, but the heavier animal usually wins most encounters and generally becomes dominant. In heterosexual pairs, the non-oestrous female has been described as very aggressive toward the male and as the dominant animal (Dieterlen 1959; Lawlor 1963; Payne \& Swanson 1970). Apparently this is not always the case and Payne \& Swanson (1970) observed instances where nonoestrous females did not fight when placed with males, and Johnston $(1970,1975)$ reported that he observed fights between males and females in only 36 per cent of the encounters between pairs. The fact that two different social patterns have been observed when female and male hamsters are placed together may reflect the pattern adopted by a particular pair of 
animals or it may indicate that some females are typically unaggressive toward males. The data are insufficient to decide between these two possibilities.

The experiments described here were designed initially to investigate male-female interactions during pregnancy and following parturition in order to determine the male behaviour tolerated by the female. In order to permit a lasting and stable relationship to develop between the sexes and to observe interactions with the pups, preand post-partum pairs of hamsters were observed in relatively large pens and kept together for several weeks in the first experiment. This arrangement made it possible to observe the conditions that permit the male to engage in 'fathering' behaviour and to more fully characterize those females that were non-aggressive toward the male. In subsequent experiments, specific hypotheses which emerged from these observations were tested by placing these and other animals together in smaller enclosures for relatively brief periods of time.

\section{Experiment 1. Prolonged Tests in Large Enclosures Methods}

The 34 mature adult (17 males and 17 females; 80 to $130 \mathrm{~g}$ ) golden hamsters were obtained from the Con Olson Company (Madison, Wisconsin). Upon arrival, heterosexual pairs were weighed and placed in plywood pens $(91.4 \times 76.2 \times 35.5$ $\mathrm{cm}$ high), which had clear Plexiglas fronts and open tops. All females were 6 to 9 days pregnant when they were received. Males were randomly placed with the females.

Sawdust ( 7 to $9 \mathrm{~cm}$ deep) was placed on the floor of the pen. A water bottle was available in one corner; food (Purina lab chow) was scattered over the sawdust. Food and water were added periodically as needed. In addition, shredded paper and two $7 \cdot 5-\mathrm{cm}$-diameter $\times$ $12.5-\mathrm{cm}-$ long metal tubes were put in each pen to provide potential nesting materials and a place of concealment. Although the animals were observed in the tubes, the nests were always built elsewhere. All pens were located in the same temperature-controlled room. Black vinyl curtains with $12 \times 20-\mathrm{cm}$ observation holes were draped in front of all pens.

Lighting was provided on a reversed (7.00 hours EST ON to 19.00 hours OFF) $12-\mathrm{hr}$ light cycle by bare, overhead $75-\mathrm{W}$ bulbs. Throughout the length of any experimental condition the sawdust was never disturbed. When the residents were changed, however, the sawdust was removed; after the sides and floor were washed, fresh sawdust, food, water and paper were placed in the pen.

Each pen was observed under dim illumination for 10 min per day, five to seven times per week during the second or third hour of darkness. Nineteen behaviour patterns (mostly taken from Dieterlen 1959) were recorded in a manner indicating the location, initiator and receiver (where applicable) and the sequence of behaviour. Duration of behaviour was not recorded. For the purposes of the present reports, only five of the behaviour patterns will be discussed, and these are described below.

When initially placed in the observation pens, ten pairs of animals were of unequal weights (in all cases the female was the lighter) and seven pairs were approximately matched for weight. A pair was considered unequal if the weight of the heavier animal exceeded by more than 11 per cent the weight of the lighter animal. All pairs were left together at least 1 week, but for up to 4 weeks if little or no aggression was observed or if the dominance relationship had not been stabilized (see below for criteria).

Following this initial observation period, the eight dominant females were paired with males matched for weight. Based on the results of the first tests, four of the females were paired with four dominant males and four females were placed with four males that were either subordinate or had been residing in neutral pens. Two of the females were tested a third time with different males. One of these males had dominated two smaller females, but had been subordinate to a female of equal weight. The other male had previously been subordinate to a female of equal weight.

In addition, four females, which had originally been residing in neutral pens, were placed with four other males of equal weight and neutral or subordinate histories. Finally, in order to test whether the neutral females would become aggressive if they were tested when they had pups present, four neutral females were each tested successively with two males. The males were placed with the females for a period up to 1 week, starting at a time when their pups were 6 to 10 days old. The eight males used for this testing had varied histories and unclear dominance records.

Description of behaviour. As already mentioned, only five of the recorded behaviour patterns were judged to be relevant to this report. 'Freezing on back' was scored only 
when an animal was seen lying flat on its back with extremities extended while the other animal was standing over or next to it. In our experience, this posture occurred only at the end of a fight. An animal sometimes turned partly on its back while attacking an opponents' underside, but this aggressive manoeuvre, which Floody \& Pfaff (1974) called the 'on back' position, could readily be distinguished from the submissive posture.

When hamsters are aggressive toward each other, they often clasp and roll over and over again in a very fast 'tumble' lasting several seconds. The tumble usually ends with one animal running away from the other. A 'chase' was scored when one animal rapidly pursued the other. The chase usually occurred after a tumble, but could occur in other circumstances. The chase often was the best index of the winner of a tumble. In addition, 'biting' sometimes occurred during or at the end of a tumble. Where it was clear which animal had initiated the biting, this information was used in determining dominance.

'Sniffing' is the most difficult behaviour to define objectively. Somewhat arbitrarily, we recorded a sniff only when an animal approached the other to within $2 \mathrm{~cm}$ distance and its nose was directed toward the nearest part of the other animal's body. The number of sniffs made it possible to distinguish those observation periods where there was no interaction at all (both animals might have been sleeping or occupied at opposite ends of the chamber) from those in which there were interactions even though the animals only sniffed each other

Criteria for relationship categories. An animal was rated 'dominant' on any one day for either chasing or biting the other animal at least twice during the $10-$ min observation period without being bitten or chased in return. On most days, dominance was very clearly asserted. For an animal to be rated dominant to its co-resident it had to have been scored as dominant for five observation periods without any reversal. There often occurred observation periods when there was little or no interaction, but these were not counted as reversals unless the previously subordinate animal was dominant on one of these days. In the two cases where one animal killed the other animal before reaching criterion, the survivor was rated dominant. Obviously, if one animal was rated as dominant its co-resident was considered to be 'subordinate'.
If there was no interaction at all between the two animals, then no rating for that day was given to either animal. If, however, each animal was observed to sniff the other animal at least five times (a minimum of ten sniffs) and there was no indication of agonistic behaviour (chasing, biting, tumbling, or submissive posturing) by either animal during the entire $10 \mathrm{~min}$, then the animals were rated neutral for that day. For animals to be rated neutral for the experiment, five such days had to occur without any intervening aggression. In one instance, animals were rated neutral because no aggression occurred during 15 observation periods even though there were not sufficient encounters to produce five neutral days.

\section{Results}

Five of the seven females matched with males of equal weight were dominant while two of these pairs had a neutral relationship. Of the ten pairs in which the female was lighter than the male, four males were dominant, three females were dominant, and three pairs were neutral (Fig. 1). No male scored a dominant day over a female before the pair had been together for 2 weeks and in two of the three cases of male dominance, the female was dominant once before the male had scored its second dominant day. Female dominance, however, usually appeared on the first day and there was only one reversal. In all cases where the weights were equal, the female either dominated or there was no aggression and the relationship was judged to be neutral. When the female was significantly lighter, there were approximately equal numbers of instances of male dominance, female dominance, and neutral relationships, but male dominance took a much longer period to establish than female dominance.

Figure 2 depicts the results of pairing hamsters with known dominance histories. In all of these pairs, the weights of the males and females were matched. If the female had been dominant she remained dominant whether the males had previously been dominant (five cases) or neutral or subordinate (five cases). Neutral females remained neutral when presented with different neutral or subordinate males (four cases).

In general, the survival rate of litters was poor. Only 7 of a total of 21 litters produced pups that survived. (The 17 females had 21 litters because four of them became pregnant 
a second time during the course of the experiment.) Pups from four out of the seven litters born in neutral pens survived, while pups from only 3 of the 14 litters from aggressive pens survived. All four neutral females with surviving pups tolerated each of two males and allowed them in the nest. No aggressive female was observed to allow a male in the nest or even near the pups unless the male was asleep. Occasionally, males were able to creep up to the edge of the nest and sleep there. Even when the females awakened, the males were left undisturbed until they awoke and started to move. Contrary to general statements that exist in the literature, the amount of aggression displayed did not increase during the course of pregnancy or when pups were present. In fact, an analysis of the observations in which males and females were making contact (as judged by the number of sniffs) indicated that aggression actually decreased following the birth of pups.

Of the eight males that were allowed to approach nests, four were seen to carry pups at least once, and two others were seen to crouch over or sleep with the pups while the mother was absent from the nest. Although neutral females were observed attempting to take the pups away from the males, no aggression was displayed during this process.

\section{Discussion}

The results clearly indicate that when male and female hamsters of matched weight are

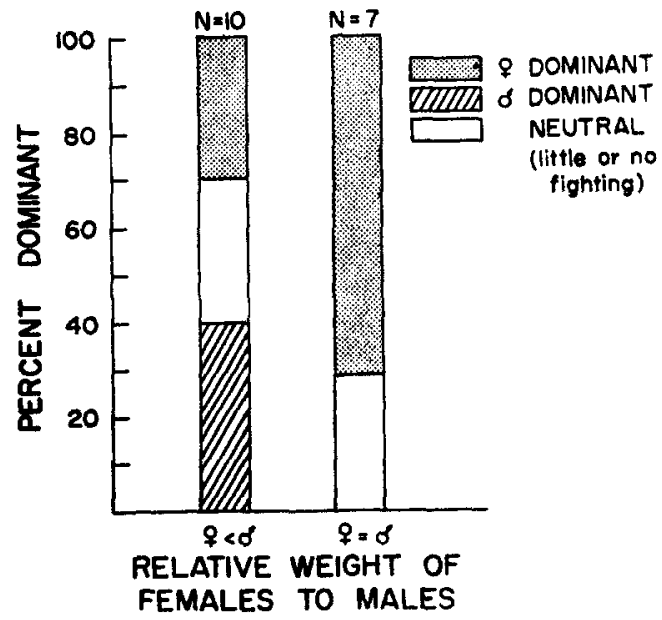

Fig. 1. Male-female dominance record as a function of relative bodyweight. A female was considered lighter if its weight was $20 \mathrm{~g}$ or more below that of the male. paired, the female determines whether or not there will be aggressive encounters. If the female is aggressive, then she is likely to dominate any male of comparable weight even if the male had previously dominated a much lighter female. If the female is non-aggressive, then she will tolerate any male and little or no fighting will occur. Although we have no observations of neutral females placed with previously dominant males, this lack of data does not appear to be critical since males were not found to dominate females of equal weight. Our results seem to support Dieterlen's (1959) conclusion that the male hamster is unlikely to show aggression toward the female, but we would have to restrict this conclusion to animals of approximately equal weight.

We have found no evidence to support the belief that the aggressiveness of the female hamster increases either as the time of parturition approaches or after the birth of the pups. If the female is tolerant toward the male, then she will not change in this respect as a result of either pregnancy or the presence of pups. In this respect, aggression in pairs of hamsters left together for extended periods of time may be different from that seen when pairs are placed together for brief periods in neutral test arenas. Using the latter testing conditions, Wise (1974) recently reported that females are more likely to attack males during the later stages of pregnancy and during lactation.

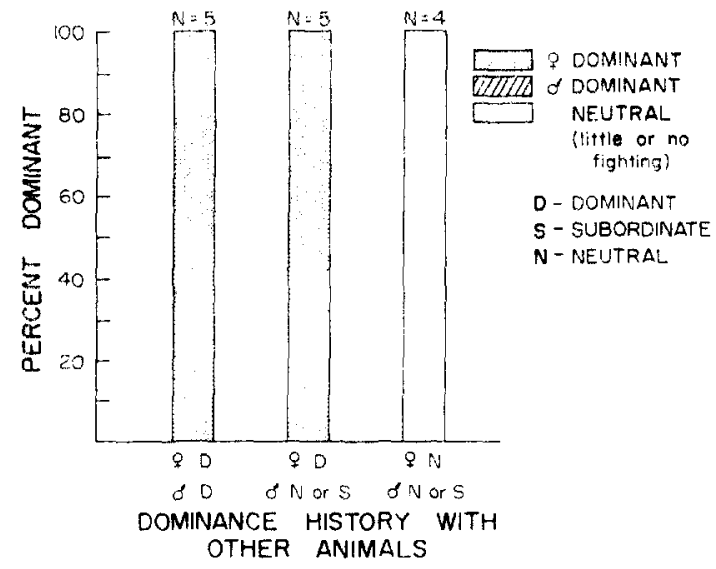

Fig. 2. Results of male-female dominance tests as a function of previous dominance record with other animals. Paired males and females were of equal weight (difference less than $20 \mathrm{~g}$ ). 
Of special interest is the fact that when the female is not aggressive the male readily exhibits 'parenting' behaviour. Males were observed sniffing, licking and carrying the pups, moving the nest, and crouching over the young. As has been suggested for mice (Dudley 1974), this behaviour may contribute in some way to the survival of the pups. The question remains to be pursued in the future. A separate report will treat the subject of 'parenting' behaviour of male and female hamsters (Marques \& Valenstein 1975). For the present, however, our observations raise the interesting possibility that in addition to the solitary pattern previously described for hamsters in the wild, there also may exist a pattern where male and female live together and the male participates in the care of the young.

An explanation of the difference between neutral and aggressive females is suggested by the finding that winners of homesexual encounters have larger flank glands than their opponents (Drickamer et al. 1973; Drickamer \& Vandenbergh 1973). These investigators have established that the size of the flank gland reflects androgen levels. Although the flank gland of females is significantly smaller than that of males, it remains a good predictor of the result of encounters between females. It was conceivable, therefore, that flank gland size also was correlated with female dominance or neutrality in heterosexual pairings. To test this possibility, we compared the diameters of the right flank glands of three neutral and six dominant females. The mean diameter of the flank glands was $4 \cdot 2 \mathrm{~mm}$ for the neutral animals and $3 \cdot 3 \mathrm{~mm}$ for the dominant females, ruling out the possibility that female flank gland size was directly related to aggressiveness toward males. This difference in gland size is not statistically significant ( $P>0 \cdot 16 ; U$-test).

Even though the size of the flank gland did not seem to be correlated with aggressiveness in heterosexual encounters, it was important to determine if the females that were not aggressive toward males were generally passive or non-combative even when tested against females or castrated males. To answer this question and to facilitate other planned experimentation, a simpler assay of individual differences in aggressiveness was developed. Neutral females from experiment 1 were tested in brief tests in small enclosures. These females were tested against each other and against three males that had been observed in the larger pens. Using this brief test procedure, we then studied the agonistic behaviour of experimentally naive females paired with each other and paired with intact and castrated males.

\section{Experiment 2. Brief Tests in Small Enclosures: Part A}

\section{Method}

The tests consisted of 15-min encounters in small pens, using a procedure very similar to that of Payne \& Swanson (1970). Testing was done in a Plexiglas chamber $(45.7 \times 30.5 \times 30.5$ $\mathrm{cm}$ high) with $5 \mathrm{~cm}$ of sawdust covering the floor. Food and water were not available. Pairs of animals were placed simultaneously in opposite corners of the pens, facing away from each other. Behaviour was recorded as before and dominance was similarly determined. The sides were cleaned and sawdust turned over between tests. If one animal scored five or more 'decisive victories' over its partner without losing any encounters during the first $5 \mathrm{~min}$, then the test was terminated at that time to prevent serious injury to the attacked animal. Otherwise, tests lasted for $15 \mathrm{~min}$. A 'decisive victory' was scored for one of three behavioural sequences: (1) when one animal chased the other after a tumble; (2) when there were tumbles and either animal ran away from the other without being chased; or (3) when one animal ended a tumble in the freezing on back position.

Three of the females rated as neutral when tested with two different males in experiment 1 were tested against each other after having been isolated in our standard wire mesh cages $(20 \times 15 \times 15-\mathrm{cm}$ high) for 6 days. The tests were given during the dark part of the cycle on a single day. Two days later, each female was given three daily tests with three different males. If a female was in oestrus during one of the testing days, she was tested on day 4 against the same male. The animals were returned to the wire mesh cages after each test. At least one of the males was matched for weight with each female.

\section{Results}

When the neutral females were placed with males, all three tolerated the constant attempts by the males to mount them during most of the 15-min periods. During one test, a single tumble occurred after $14 \mathrm{~min}$ elapsed. Chasing or other indications of dominance or subordinateness did not occur. Therefore, there was no winner in this single aggressive encounter. In sharp 
contrast to these results, all three neutral females tested fought vigorously against each other with a maximum latency of $1.5 \mathrm{~min}$ before the onset of fighting. All the fights had to be terminated at $5 \mathrm{~min}$ because five or more 'decisive victories' had taken place by that time.

\section{Experiment 2: Part B}

In part A it was demonstrated that females rated as neutral in the prolonged testing in large pens remained neutral when placed together with males in a brief test in small enclosures. To further substantiate the usefulness of the brief test in small enclosures, part B was designed to test the reliability of this procedure for determining differences in female aggressiveness toward intact males and the preliminary results suggesting that females can elicit aggression from females that do not attack intact males. In addition, females were tested with castrated as well as intact males.

\section{Method}

The 30 experimentally naive, adult hamsters ( 20 males, 10 females) used in this experiment were obtained from the Con Olson Company (Madison, Wisconsin). Each was weighed, earpunched (numbered) and individually housed in a rack of $20 \times 15 \times 15-\mathrm{cm}$ high wire mesh cages in a room with a reversed light cycle. Testing began 1 week after their arrival. Ten males were castrated shortly after arrival and 2 weeks prior to their use in testing. Throughout the entire experiment, food and water were administered ad libitum.

Each female was matched for weight (differences less than $10 \mathrm{~g}$ ) with three males and tested, as in part $\mathrm{A}$, with one male on each of three successive days. To test for reliability, each female was matched with and tested against three different males 1 week after the completion of the first series of tests. One week following the retest with males, each female was paired with three of the castrated males. Because castrated hamsters are unusual among mammals in that they gain weight faster than intact animals, the castrated males in this experiment were heavier than the females by as much as $25 \mathrm{~g}$. The average weight of the castrated males was $120 \mathrm{~g}$ compared to $108 \mathrm{~g}$ for the females. Finally, the four most aggressive females were paired with the four least aggressive females, after all ten were rank-ordered according to the total number of tumbles and chases that occurred in tests against normal males. Only tumbles and chases that were not lost were counted in ranking aggressiveness. Tumbles without winners were counted because (as pointed out by Floody \& Pfaff 1974) in such cases both animals are usually aggressive.

\section{Results}

The aggressive rank of the females during the first three tests with intact males was significantly correlated with the rank obtained during the second series of three tests (Spearman rank correlation coefficient, $\left.r_{\mathrm{S}}=0.70 ; P<0.04\right)$. This test-retest consistency indicates that brief tests in small enclosures are useful for distinguishing females that differ widely in their aggressiveness toward intact males. The two least aggressive females, for example, engaged in a total of zero and three fights in the two series of tests, while the two most aggressive females fought 36 and 28 times, respectively, in their tests. In contrast, the rank correlation of male aggressiveness over tests was not significant $(P>0 \cdot 20)$, suggesting that it is the female that is the major determinant of aggressiveness.

Even though there were consistent differences in the aggressive behaviour of the females, a high level of aggression was not observed. No test had to be terminated before the full $15 \mathrm{~min}$ had elapsed because of the intensity of aggression. In 7 of 60 encounters, the male won more decisive victories than the female. Apparently a male of equal weight to a female may dominate in a brief encounter in a neutral environment even though the results obtained in experiment I suggested that this was an unlikely outcome during a more prolonged period of interaction. No male won consistently, however, as the seven male victories involved five males.

Although the relative amount of aggression displayed during the brief tests with intact males was not high, a considerable amount of aggression occurred when the females were tested against castrated males or other females. When tested against castrated males, the aggressiveness of the females increased significantly $(P<0.02$, Wilcoxon matched-pairs, signed-ranks test). For comparison purposes, females were ranked (lowest ranked was the least aggressive) according to their average number of tumbles and chases not lost over the six tests with normal males. Figure 3 shows the frequency of such aggressive behaviour per encounter against normal and against castrated males as a function of rank against normal males. There was no significant correlation 
between the aggressive rank with intact and castrated males. Testing of two females (one with the rank of 3.5 and the other with rank of 9) had to be terminated at 5 min because of the amount of aggression displayed against castrates. The animal with rank 9 had two tests terminated and the other had only one. Only one castrated male won more decisive victories than its female combatant and this occurred during only one test.

Of the four encounters between the females that were most and least aggressive against intact males, three had to be terminated at the end of $5 \mathrm{~min}$. Two of the encounters were won by previously unaggressive females and two were won by females which were aggressive against normal males.

\section{Discussion}

In part $A$ the reliability of a brief test in a small enclosure for determining the relative aggressiveness of female hamsters toward intact males was established. Females judged to be neutral when housed with males remained neutral when placed together with males in a brief test in small enclosures. In part $\mathbf{B}$, females that were unaggressive toward intact males displayed considerable aggression when placed with castrated males or other females. This result together with the fact that they won an equal number of encounters when placed with 'aggressive' females indicates that females which are unaggressive toward intact males, are not generally unaggressive or submissive.

\section{General Discussion}

Female hamsters differ widely among themselves in the amount of aggressiveness displayed toward intact males. When males and females of equal weight are paired in large enclosures, most females are very aggressive and keep the subordinate male at a distance, except when they are in oestrus. Some of the females (in our sample approximately 29 per cent) are very tolerant of males and display little or no aggression toward them. If the males are significantly heavier (more than $20 \mathrm{~g}$ ), then they

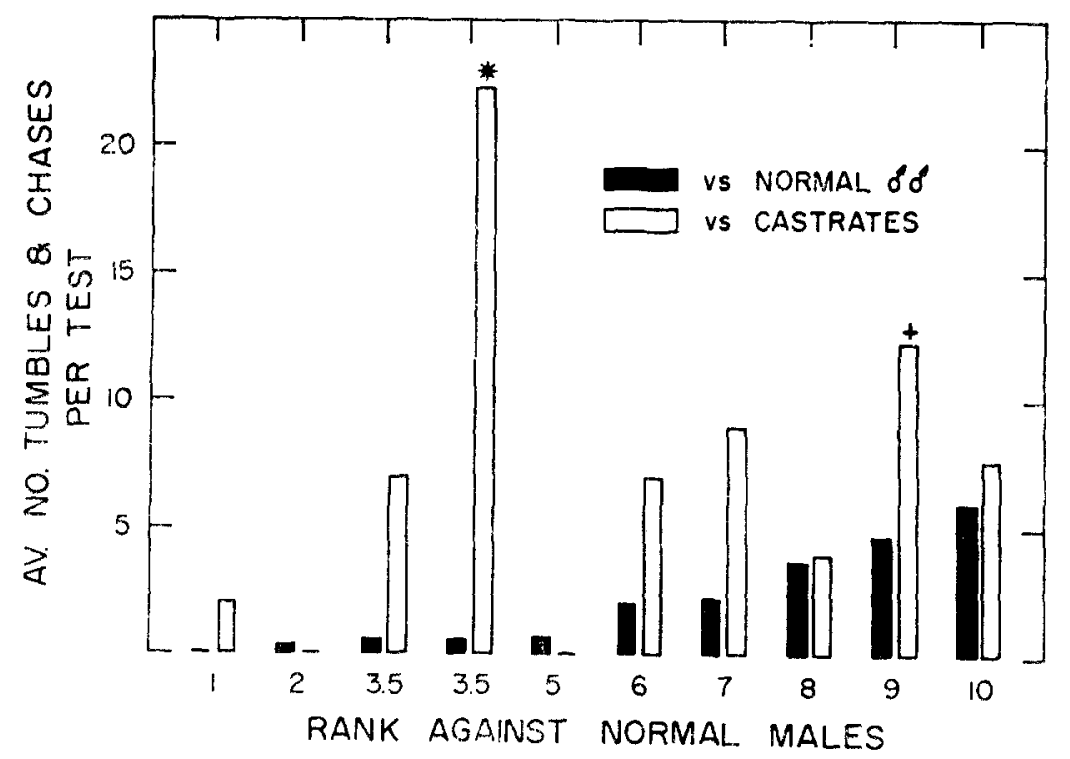

Fig. 3. Comparison of aggressiveness of female hamsters toward intact and castrated males. The ten females were ranked in order of aggressiveness toward intact males (higher ranks indicate greater aggressiveness). Aggressiveness was measured by the average number of tumbles and chases (not lost) a female engaged in during the 15 -min tests. Results are based on six tests with intact males and three with castrates. A conservative estimate of the aggression that would have occurred in those tests that had to be terminated (because of the intensity of aggression) was obtained by doubling the 5 -min score. $(-)=2$ tests terminated; $(*)=1$ test terminated. 
may dominate the female, which occurs in about 40 per cent of such pairings.

During prolonged testing conditions, where there is no weight disparity, the pattern of interaction seems to be completely determined by the female. Females that are aggressive toward males are aggressive toward all males, while those that accept males will accept all of them. The females that display little aggression toward males do not change when they have young. The males are permitted to sleep in the nest, retrieve young, crouch over them, and to move the nest site without eliciting aggression from the female.

The aggressiveness of female hamsters can be conveniently and reliably assessed in brief tests in small enclosures. A wide range of differences in the amount of aggressiveness females display toward males can be observed in these brief tests and the results are in general agreement with those obtained when animals are living together for longer periods, although instances were observed where males dominated females of the same weight. This dominance occurred in 12 per cent of the encounters.

The females that do not aggress against intact males are not generally unaggressive. When such females are paired with either castrated males or other females (including those that are aggressive toward intact males), they are usually very aggressive. Superficially, our observations of increased female aggressiveness toward castrated males seem to conflict with Payne \& Swanson's (1972) conclusion that females respond similarly to normal and castrated males. However, their 'normal' males were castrates receiving testosterone propionate. A comparison group of females tested also with intact males was not included in their study. In view of the recent report by Payne (1974) that androgens differ in their effect on male hamsters, it is unlikely that a castrate receiving testosterone propionate is equivalent to an intact animal in all respects. The striking differences we observed in female aggressiveness toward intact and castrated males in experiment 2 have convinced us that the phenomenon is real.

\section{Acknowledgments}

The authors gratefully acknowledge the support of N.I.M.H. Research Grant 2 R01 MH2081103.

\section{RE F E R E N C E S}

Dieterlen, F. (1959). Das Verhalten des Syrischen Goldhamsters. Z. Tierpsychol., 16, 47-103.
Drickamer, L. C. \& Vandenbergh, J. G. (1973). Predictors of social dominance in the adult female golden hamster (Mesocricetus auratus). Anim. Behav., 21, 564-570.

Drickamer, L. C., Vandenbergh, J. G. \& Colby, D. R. (1973). Predictors of dominance in the male golden hamster (Mesocricetus auratus), Anim. Behav., 21, 557-563.

Dudley, D. (1974). Contributions of paternal care to the growth and development of the young in Peromyscus californicus. Behav. Biol, 11, 155-166.

Eibl-Eibesfeldt, I. (1953). Zur Ethologie des Hamsters (Cricetus cricetus L.). Z. Tierpsychol., 10, 204-254.

Elliott, C. W. (1955). Polygamous male. National Chinchilla Breeder, 18-20 May.

Floody, O. R. \& Pfaff, D. W. (1974). Steroid hormones and aggressive behavior: approaches to the study of hormone-sensitive brain mechanisms for behavior. In: Aggression (Ed. by S. H. Frazier), pp. 149-185. Baltimore: Williams \& Wilkins.

Johnston, R. E. (1970). Scent-marking, olfactory communication, and social behavior in the golden hamster. Mesocricetus auratus. Ph.D. thesis, Rockefeller University, New York.

Johnston, R. E. (1975). Scent marking by male golden hamsters (Mesocricetus auratus). I. Effects of odors and social encounters. $Z$. Tierpsychol., 37, 75-98.

Jolly, A. (1966). Lemur Behavior: A Madagascar Field Study. Chicago: University of Chicago Press.

Klauer, P. (1969). Changing to polygamous matings. In: Rancher's Handbook. Empress Chinchilla Breeders Cooperative, Inc,, 8th edn.

Lawlor, M. (1963). Social dominance in the golden hamster. Bull. Br. psychol. Soc., 16, 25-38.

Leonard, C. (1972). Effects of neonatal (day 10) olfactory bulb lesions on social behavior of female golden hamsters (Mesocricetus auratus). J. comp. physiol. Psychol., 80, 208-215.

Lerwill, C. J. (1968), Agonistic behaviour and social dominance in the golden hamster (Mesocricetus auratus Waterhouse). Master's thesis, University College, Swansea.

Marques, D. M. \& Valenstein, E. S. (1975). Parenting behavior in male and female hamsters. Submitted for publication.

Melton, E. R. (1950). A preliminary study of dominance subordination relationships in the golden hamster. J. Colo. Wyo. Acad. Sci., 4, 77.

Payne, A. P. (1974). A comparison of the effects of androstenedione, dihydrotestosterone, and testosterone propionate on aggression in the castrated male golden hamster. Physiol. \& Behav., 13, 21-26.

Payne, A. P. \& Swanson, H. H. (1970). Agonistic behaviour between pairs of hamsters of the same and opposite sex in a neutral observation area. Behaviour, 36, 259-269.

Payne, A. P. \& Swanson, H. H. (1972). The effect of sex hormones on the agonistic behavior of the male golden hamster (Mesocricetus auratus Waterhouse). Physiol. \& Behav., 8, 687-691. 
Rowell, T. E. (1971). Organization of caged groups of cercopithecus monkeys. Anim. Behav., 19, 625645.

Struhsaker, T. T. (1967). Social structure among vervet monkeys (Cercopithecus aethiops). Behaviour, 29, $83-121$.

Swanson, H. H. (1967). Alteration of sex-typical behavior of hamsters in open field and emergence tests by neonatal administration of androgen or cestrogen. Anim. Behav., 15, 209-216.

Wise, D. A. (1974). Aggression in the female golden hamster: Effects of reproductive state and social isolation. Hormones and Behaviour, 5, 235-250.

(Received 28 April 1975; revised 21 August 1975; $M S$. number: A1708) 